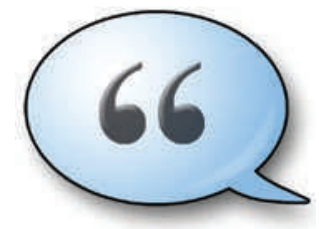

HAVE YOUR SAY

Comment on any of our News stories, online.

www.nature.com/news

\title{
Japan plans nuclear power expansion
}

\section{Proposal for eight new reactors and nuclear fuel reprocessing faces public opposition.}

Like most countries that embraced nuclear power decades ago, Japan has soured on the technology in recent years. But prompted by worries about climate and energy security, the country's industry ministry last week placed a big bet on a rapid expansion of its nuclear power capability.

When the draft energy plan is finalized and signed by the Japanese cabinet in June, it will stand as a roadmap for the country's new government, which campaigned on a platform of reducing carbon emissions by $25 \%$ below 1990 levels by 2020 - a promise that is unpopular with the business community. But despite the government's nuclear ambitions, individual reactors will still need approval from local authorities, which is far from certain.

Japan relies on imports for more than $80 \%$ of its total energy needs; the plan aims to reduce that figure to just $30 \%$ by 2030 . "With the balance of energy demand changing dramatically we really have to think about energy security," says Ken Sasaji, director of the ministry's energy planning office.

Japan already has 54 reactors with a total generating capacity of 49 gigawatts, accounting for about a quarter of its electricity supplies (see 'Japan's energy mix'). But following a series of accidents between 1997 and 2007, growing public resistance meant that only five reactors were built in the past decade. The new plan proposes building eight reactors by 2020 to supply an additional 11.4 gigawatts of electricity.

To ensure that those reactors have fuel, Japan forged a nuclear-energy deal in March with Kazakhstan, which holds the world's secondlargest uranium reserves and mines about $20 \%$

\section{JAPAN'S ENERGY MIX}

Japan is one of the world's leading producers of nuclear power, which meets a substantial proportion of its electrical energy needs.

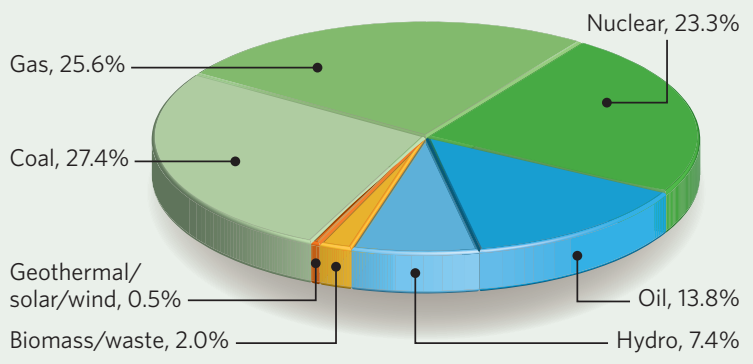

Total electricity generated in 2007: 1,134 terawatt hours of the world's uranium ore, making it the world's biggest producer. Japan has promised to supply nuclear-energy technology to Kazakhstan in return for a stable supply of uranium.

And last week, Itochu, a Tokyo-based trading company backed by the government, bought a $15 \%$ stake in Kalahari Minerals, headquartered in London, which is developing a large uranium mine in Namibia. The mine is expected to begin producing more than 5,000 tonnes of uranium per year in 2013 - roughly $10 \%$ of the total uranium mined around the world in 2008.

Japan is also counting on its nuclear recycling programme, which recently started after years of failed efforts to convince local residents of its necessity and safety (see Nature 440, 138; 2006). In December 2009 , a reactor on the southern island of Kyushu started burning mixed oxide fuel, made by mixing uranium with plutonium from spent fuel. And in February, the Japanese Nuclear Safety Commission gave its approval for a restart of the Monju fast-breeder test reactor in Tsuruga, which will use some of the neutrons generated during the fission process to turn non-fissile uranium isotopes into plutonium that can be extracted from the spent fuel.

There are also plans to squeeze extra energy from the country's existing reactors, some of which are around 40 years old. At a 19 March meeting of the US-Japan Nuclear Energy Steering Committee in Washington DC, the partners agreed to collaborate on studies aimed at extending the life of old reactors.

But the Japanese government will face a struggle to secure public acceptance of its nuclear ambitions, which are open for public

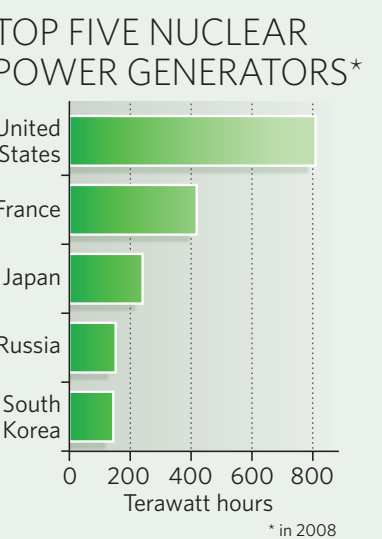

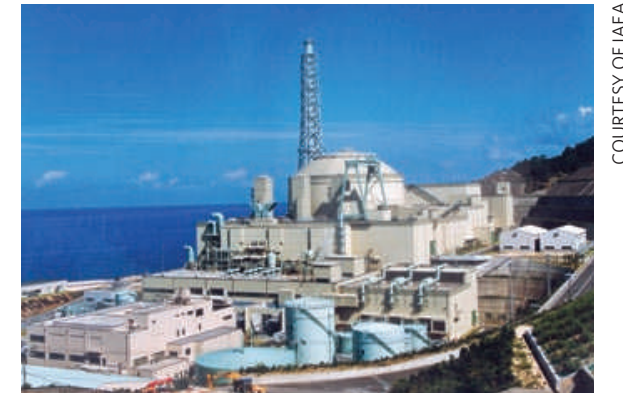

The Monju prototype reactor is set to restart.

comment until 7 April. Confidence in nuclear power was shaken in 2007 when a magnitude- 6.8 earthquake caused a shutdown of the Kashiwazaki-Kariwa plant in Niigata after radioactive cooling water leaked into the sea (see Nature 448, 392-393; 2007).

And fresh objections are being raised about Monju. After decades of experimentation, most countries with significant nuclear capabilities have given up on fast-breeder technology, partly because of safety concerns. Monju itself has been closed since 1995 when leaking coolant damaged the plant, and a cover-up attempt damaged the plant's reputation.

With safety and earthquake-resistance tests completed in February, the Japan Atomic Energy Agency, which runs Monju, now only needs the local Fukui government to sign on.

On 11 March, however, 29 scientists opposed to restarting Monju released a letter on the Citizens' Nuclear Information Center website claiming that checks of key pipes have been inadequate and that the current reactor set-up does not serve as a useful prototype for future fast-breeder reactors. The group argues that because Monju's construction costs were five times greater than a conventional reactor, a fullscale plant would have to be very different from the Monju protoype to be commercially viable.

Japan's situation contrasts with that of its neighbour, China, where more than 20 reactors are under construction and face little public opposition. China aims to reach at least 70 gigawatts of nuclear power by 2020 .

For Japan, eight new reactors over the next decade will be a struggle, says Takuyuki Kawauchi of the industry ministry's nuclearenergy policy division. "We can't just start putting reactors wherever we want," he says. "We have to get the understanding of the local residents, and that takes time."

David Cyranoski 